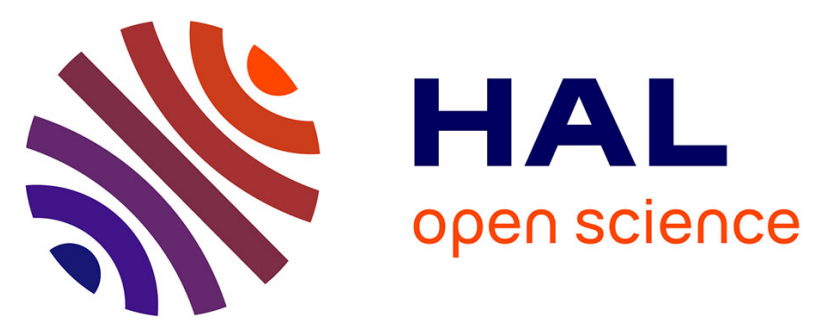

\title{
The role of cold storage and seed source in the germination of three Mediterranean shrub species with contrasting dormancy types
}

\author{
Ana Vasques, V. Ramón Vallejo, M. Conceição Santos, J. Jacob Keizer
}

\section{- To cite this version:}

Ana Vasques, V. Ramón Vallejo, M. Conceição Santos, J. Jacob Keizer. The role of cold storage and seed source in the germination of three Mediterranean shrub species with contrasting dormancy types. Annals of Forest Science, 2014, 71 (8), pp.863-872. 10.1007/s13595-014-0395-z . hal-01102957

\section{HAL Id: hal-01102957 \\ https://hal.science/hal-01102957}

Submitted on 13 Jan 2015

HAL is a multi-disciplinary open access archive for the deposit and dissemination of scientific research documents, whether they are published or not. The documents may come from teaching and research institutions in France or abroad, or from public or private research centers.
L'archive ouverte pluridisciplinaire HAL, est destinée au dépôt et à la diffusion de documents scientifiques de niveau recherche, publiés ou non, émanant des établissements d'enseignement et de recherche français ou étrangers, des laboratoires publics ou privés. 


\title{
The role of cold storage and seed source in the germination of three Mediterranean shrub species with contrasting dormancy types
}

\author{
Ana Vasques • V. Ramón Vallejo • M. Conceição Santos • \\ J. Jacob Keizer
}

Received: 26 November 2013 / Accepted: 5 June 2014 / Published online: 24 June 2014

(C) INRA and Springer-Verlag France 2014

\begin{abstract}
- Context The use of native species in ecological restoration is highly recommended but, in practice, it is often impaired by knowledge gaps in the germination ecology of suitable species.

- Aims This study aimed to assess the role of storage conditions and seed source on the germination of three Mediterranean shrub species with contrasting types of dormancy.

- Methods Ripe fruits were harvested at two or three distant locations in mainland Portugal. Seeds were subjected to three treatments consisting in different storage conditions: cold storage at low and high moisture conditions, plus a control. Five replicates of up to 30 seeds were placed under constant
\end{abstract}

\footnotetext{
Handling Editor: Douglass Jacobs

Contribution of the co-authors Ana Vasques: Experimental design, species selection, data collection, data analysis and writing the paper.

V. Ramón Vallejo: Experimental design, species selection, intermediate reviews, logistical support, supervision.

Conceição Santos: Experimental design, logistical support, supervision. J. Jacob Keizer: Experimental design, intermediate reviews, logistical support, supervision
}

A. Vasques $(\square) \cdot$ J. J. Keizer

Centre for Environmental and Marine Studies (CESAM),

Department of Environment and Planning, University of Aveiro,

Campus Universitário de Santiago, 3810-193 Aveiro, Portugal

e-mail: ana.vasques@ua.pt

\section{C. Santos}

Centre for Environmental and Marine Studies (CESAM), Department of Biology, University of Aveiro, Campus Universitário de Santiago, 3810-193 Aveiro, Portugal

V. R. Vallejo

Mediterranean Center for Environmental Studies (Foundation

CEAM) Parque Tecnológico C/Charles R. Darwin,

1446980 Paterna, Spain temperature conditions and germination was monitored weekly during 14 weeks.

- Results The effect of cold storage at high moisture on germination differed between the three species and seed source played a significant role in the germination of all three species. In the case of the species with dormancy, the observed differences in germination could reflect changes in the species' dormancy degree or sensitivity to dormancy breaking factors across their geographical range. In the case of Pistacia lentiscus (no dormancy), the results suggested a possible adaptation of the northern seed source to high moisture conditions.

- Conclusions The observed differences between species agreed well with their dormancy types, and the seed sourcerelated differences could be adaptive features, as they seemed related with local climate conditions.

Keywords Arbutus unedo $\cdot$ Phillyrea angustifolia $\cdot$ Pistacia lentiscus · Ecological restoration - Germination ·

Mediterranean $\cdot$ Seed source

\section{Introduction}

Mediterranean plant communities are increasingly threatened by inadequate management (Díaz-Delgado et al. 2002; Pausas et al. 2008; Scarascia-Mugnozza et al. 2000). Climate change scenarios are expected to aggravate degradation processes through an increase in the frequency and severity of summer droughts and forest fires (Solomon 2007; Vallejo et al. 2012). Restoration actions involving seeding or planting are increasingly required to reverse land degradation processes (Vallejo et al. 2005).

In restoration actions, ex situ conservation protocols for native species assume a particular importance (Merritt and Dixon 2011). While the use of native species is highly 
recommended, it often presents major challenges with respect to the availability of seeds as well as the definition of adequate seed harvesting, storage and seeding protocols (Tischew et al. 2011; Oliveira et al. 2011). The successful use of seeds in restoration actions critically depends on the one hand on appropriate storage methods to maintain seed viability, but on the other hand on the knowledge of the conditions that will break seed dormancy (Merritt and Dixon 2011). According to Oliveira et al. (2011), the main drawbacks for predicting germination success in many native species are the knowledge gaps regarding the presence of different types of dormancy and the correspondent dormancy breaking mechanisms.

Seed dormancy is defined as the inability of seeds to germinate under conditions that otherwise would favour their germination (Baskin and Baskin 2004). The main types of seed dormancy are physiological and physical dormancy (Baskin and Baskin 2004; Taiz and Zeiger 2010). Physiological dormancy is associated with the hormone balance of the embryo and requires specific external stimuli to be terminated, while physical dormancy is associated to the seed coat, which acts as a physical barrier, inhibiting the entrance of water into the seed (Murdoch and Ellis 2000; Finch-Savage and Leubner-Metzger 2006).

The dormancy type of a species determines its overall germination response, i.e. the type of initiation stimuli that are necessary to break dormancy and the range of temperature and water potential conditions that allows germination (Murdoch and Ellis 2000). Dormancy is not a fixed but a dynamic state that can be present in different degrees (FinchSavage and Leubner-Metzger 2006; Long et al. 2014). The degree of dormancy (in the case of physiological dormancy) or the sensitivity to dormancy breaking factors (in the case of physical dormancy) can vary in response to environmental stimuli during seed development as well as following dispersal (Long et al. 2014). A greater sensitivity to dormancy breaking factors implies that a broader range of conditions, including in terms of temperature and water potential, can induce germination (Fenner and Thompson 2005; Long et al. 2014).

Differences in dormancy have been invoked to explain differences in germination, between seeds of the same fruit and also from different fruits, mother plants and plant populations (Murdoch and Ellis 2000). In general, warmer conditions during seed development lead to a lower degree of dormancy (Long et al. 2014). In this sense, seeds from populations with distinct climate conditions have been found to differ in germination (Bischoff et al. 2008; Mijnnsbrugge et al. 2010; Vasques et al. 2012). Nonetheless, the role of seed source remains hard to predict, including because different species do not tend to respond in the same manner to similar conditions during seed development or following dispersal. For example, cold stratification has been found to either enhance or eliminate differences in germination between seed sources, depending on the species studied (Milberg and Andersson 1998).

Seed dormancy together with seed size and seed dispersal mechanisms are key plant traits in determining where and when the seeds will germinate. Thus, these traits play an important role in regulating the spatio-temporal dynamics of vegetation community composition under a variety of changing environmental conditions (Venable and Brown 1988; Fenner and Thompson 2005).

The three species selected for this study-Arbutus unedo L., Pistacia lentiscus L. and Phillyrea angustifolia L.-are evergreen tall shrubs to small trees that often co-exist in the understory of forests dominated by Quercus spp. or Pinus spp. trees (Directiva Habitats 1992). All the three species have fleshy fruits that are dispersed by vertebrates (Herrera 1984, 1989) and none of them form a persistent seed bank (Cerabolini et al. 2003). They also have a low to moderate flammability, reflecting a limited accumulation of dead aboveground biomass (Liodakis and Kakardakis 2008) as well as a strong ability to resprout following damage, therefore contributing to ecosystem resilience (Vallejo et al. 2005; 2012).

Intensive disturbance regimes, possibly combined with unfavourable climate conditions during the initial recovery phase, are expected to endanger the persistence of the three species studied here (Pratt et al. 2013). Thus, in highly disturbed scenarios the lack of a persistent soil seed bank could per se justify the re-introduction of these species through ecological restoration.

An important criterion in selecting the three species studied here was their similar period of seed dispersal (autumn-winter), which conducts to the exposure to similar post-dispersal environmental conditions, i.e. cold and humid. The combination of high moisture and temperature conditions is known to favour seed aging, thus affecting negatively the seed vigour. Still, the exposure of imbibed seeds to cold conditions cold conditions in imbibed seeds has been found to induce the production of gibberellins, which, in turn, are known to promote germination in seeds with physiological dormancy (Penfield et al. 2005). Germination in seeds with physical dormancy is also influenced by temperature but not by moisture conditions, as the intact seed coat is impermeable to water entry (Long et al. 2014). Thus, cold but low moisture conditions are generally advised for ex situ conservation of orthodox seeds (Engelmann and Engels 2002).

A second key criterion in selecting the three species was that they represented the two principal types of dormancy: physical dormancy in the case of P. angustifolia (according to García-Fayos (2001)); physiological dormancy in the case of A. unedo (according to Tilki (2004)); and lack of dormancy in the case of P. lentiscus (according to García-Fayos and Verdu (1998) and García-Fayos (2001)).

Based on the species-specific dormancy types, we hypothesized that cold storage under high moisture conditions would: (i) enhance germination in A. unedo; (ii) either 
increase or have no effect on germination in P. angustifolia; (iii) either have no effect or decrease germination in $P$. lentiscus. The effects of the treatments on P. angustifolia as well as on P. lentiscus were expected to depend on how susceptible the seeds would be to lose viability under high moisture conditions (Roberts 1973; Murdoch and Ellis 2000).

The overall aim of this study was to further the understanding of the germination ecology of three shrub species with special interest for ecological restoration of Mediterranean plant communities. Particular relevance was given to the role of different seed sources from distant regions in Portugal, which present contrasting climate conditions, also because seeds from regional sources are highly recommended in restoration actions to avoid outbreeding depression (Hufford et al. 2012). The study's specific objectives were the following: (i) to assess if the germination responses of the three selected species to cold storage would fit in with their contrasting types of dormancy; (ii) to determine if the germination responses of the three species varied between distant populations in Portugal with different temperature and rainfall regimes; (iii) to explore if possible differences in the germination response of distinct seed sources could be linked to differences in site-specific environmental conditions during the seeds' permanence in the soil seed bank in winter and, as such, could represent adaptations to local conditions.

\section{Material and methods}

\subsection{Species distribution and sampling sites}

Three evergreen Mediterranean shrub species-P. lentiscus (Anacardiaceae), P. angustifolia (Oleaceae) and A. unedo (Ericaceae) - were selected to represent different types of dormancy but comparable periods of seed dispersal (as detailed in the introduction).

P. lentiscus has a termophilous geographical distribution pattern and is exclusive to the Mediterranean Basin and Macaronesia (Palacio et al. 2005; JBUTAD et al. 2014). In mainland Portugal, P. lentiscus occurs in approximately two thirds of the territory, and the northern population studied here is located at the north-western limit of the species' distribution (JBUTAD et al. 2014; Table 1). P. angustifolia has a distribution that is limited to the central and western a parts of the Mediterranean Basin and that includes almost the entire mainland of Portugal, with the exception of some sparse areas (JBUTAD et al. 2014). A. unedo has the widest geographical distribution of the three species studied, occurring in Ireland, Southern Europe, Northern Africa, Palestina and Macaronesia. In mainland Portugal, $A$. unedo can be found throughout the entire territory (JBUTAD et al. 2014).

The geographical location, climate (long-term annual mean temperature and annual precipitation) and predominant soil type of the sampling sites are given in Table 1 . The populations that were sampled in this study differed noticeably in temperature but especially rainfall conditions, reflecting the strong climatic gradient that is present from northern to southern Portugal (Peel et al. 2007). Annual rainfall is, on average, approximately 20 to $40 \%$ lower at the central than northern study sites and approximately $25 \%$ lower at the southern than central sites (Table 1).

The exact locations of the sampled populations were selected by doing field surveys of the geographical areas that had been defined on forehand. The surveys aimed at identifying populations with sufficiently large numbers of plant specimen presenting ripe fruits, which in practice, came to mean populations ranging from approximately 25 to more than 1,000 plants, within a target area of approximately $1 \mathrm{~km}^{2}$. The sampling sites of $P$. lentiscus and $P$. angustifolia corresponded to shrublands that included individual trees but lacked a dominant tree layer, so that the sampled mother plants were small shrubs of less than $1.5 \mathrm{~m}$ high. These shrublands included, besides $P$. lentiscus and P. angustifolia, Myrtus communis L. and Cistus spp. as common elements, which, in its turn, were accompanied by Crataegus monogyna Jacq., Ruscus aculeatus L., Quercus faginea Lam. and Laurus nobilis L. at the northern sampling site, by Olea europaea L., Daphne gnidium L., and Pinus pinea L. at the central site, and by Corema album (L.) D.Don and P. pinea at the southern site. The sampling sites of $A$. unedo corresponded to Pinus pinaster Aiton plantations where it occurred in the understorey as tall shrubs $2-4 \mathrm{~m}$ high. Other companion species at these sites were Erica spp. and Quercus spp. in the northern location, Calluna vulgaris (L.) Hull, Erica spp., Pterospartum tridentatum (L.) Willk., and Ulex sp. in the central location, and Cistus ladanifer L., Quercus suber L. and Ulex sp. in the southern site.

\subsection{Seed harvesting and handling}

Seeds were harvested during the autumn of 2009 , more precisely between November 12 and December 19. After identifying a target sampling area of approximately $1 \mathrm{~km}^{2}$, ten mother plants were selected in a random manner but excluding plants that lacked sufficient ripe fruits, that showed apparent signs of damage or disease and that were located at less than $5 \mathrm{~m}$ distance from a previously selected plant. A suitable population of $P$. angustifolia could not be found in the previously-defined area in northern Portugal, in spite of an intensive survey campaign. Furthermore, the $P$. angustifolia populations selected at the central and southern sites lacked sufficient mother plants with ripe fruits, so that only five and nine plants were sampled, respectively. In the case of $P$. lentiscus, it was not possible to limit sampling to mother plants with sufficient black fruits, so that red fruits had to be harvested from various specimens. Based on the findings of 
Table 1 Geographical coordinates, long-term annual mean temperature and annual precipitation (IPMA: data from 1981 to 2010, https:/www.ipma.pt/pt/ oclima/normais.clima/) and principal soil type (Cardoso et al. 1973) for the different seed harvesting sites of P. lentiscus, P. angustifolia and A. unedo

\begin{tabular}{|c|c|c|c|c|c|c|c|}
\hline Species & District & Site & Latitude & Longitude & $\begin{array}{l}\text { Annual mean } \\
\text { temperature }\left({ }^{\circ} \mathrm{C}\right)\end{array}$ & $\begin{array}{l}\text { Annual precipitation } \\
(\mathrm{mm})\end{array}$ & $\begin{array}{l}\text { Principal soil } \\
\text { type }\end{array}$ \\
\hline \multirow{3}{*}{$\begin{array}{l}\text { Pistacia lentiscus and } \\
\text { Phillyrea angustifolia }\end{array}$} & Aveiro & Northern & $40^{\circ} 17^{\prime}$ & $8^{\circ} 90^{\prime}$ & 15.6 & 938 & Cambisol \\
\hline & Setúbal & Central & $38^{\circ} 45^{\prime}$ & $9^{\circ} 06^{\prime}$ & 16.6 & 735 & Luvisol \\
\hline & Faro & Southern & $37^{\circ} 19^{\prime}$ & $8^{\circ} 50^{\prime}$ & 17.9 & 509 & Luvisol \\
\hline \multirow[t]{3}{*}{ Arbutus unedo } & Braga & Northern & $37^{\circ} 50^{\prime}$ & $8^{\circ} 40^{\prime}$ & 15.0 & 1,449 & Cambisol \\
\hline & Coimbra & Central & $40^{\circ} 14^{\prime}$ & $7^{\circ} 99^{\prime}$ & 16.0 & 886 & Cambisol \\
\hline & Faro & Southern & $31^{\circ} 14^{\prime}$ & $8^{\circ} 48^{\prime}$ & 17.9 & 509 & Luvisol \\
\hline
\end{tabular}

Verdú and García-Fayos (1998; 2000), red fruits from P lentiscus can be expected to contain higher percentages of abnormal seeds than black fruits. This possible bias was counterbalanced by excluding the floating fruits and seeds.

The harvested fruits were handled following a standardized protocol and for each individual mother plant separately. The first step of the protocol involved using a blender to separate the seeds from the fruit pulp. The seeds were then washed under running water and set to dry over filter paper for 2 weeks (García-Fayos 2001). The seeds were subsequently stored in hermetic glass bottles, using a layer of cotton and silica to guarantee low moisture conditions (6-8 \%). The bottles were kept in the dark and at room temperature for 2-3 months until the start of the treatments. Before the actual start of the germination experiment, all seeds were subjected to a careful visual inspection and those with apparent signs of damage were excluded.

\subsection{Treatments and experimental setup}

Two cold storage treatments were selected to simulate conditions following seed dispersal in autumn-winter. These treatments consisted of storing the seeds in a cold chamber at 4$5{ }^{\circ} \mathrm{C}$ and in the dark for 10 weeks prior to the actual germination tests, either under low moisture conditions (LM) or under high moisture conditions (HM). The LM conditions involved maintaining the seeds in hermetic glass bottles (as described in the previous section), while the HM conditions involved adding vermiculite that was previously wetted to field capacity (free drainage was negligible) to the bottles and mixing it thoroughly with the seeds. The control treatment consisted of maintaining the seeds in the hermetic glass bottles at room temperature.

The germination tests comprised five replicates, each of which with up to 30 seeds. The seeds of each replicate consisted of three randomly selected seeds from each of the mother plants that, after being soaked for $24 \mathrm{~h}$, were placed in a Petri dish using a regular grid. The Petri dishes were placed in a random scheme in a room with controlled conditions of temperature $\left(20^{\circ} \mathrm{C}\right)$ and photoperiod $(16: 8)$. Germination was assessed at weekly intervals during a period of 14 weeks and was considered to have occurred when the radicle had emerged from the testa.

In the case of $P$. angustifolia, three further treatments were selected to specifically address the physical dormancy of the seeds (García-Fayos 2001; Piotto and Di Noi 2001). Two of them followed the same experimental setup as described above but involved an additional pre-treatment of the seeds: (i) heat exposure in a laboratory oven at $120{ }^{\circ} \mathrm{C}$ for $5 \mathrm{~min}$, based on the findings of Salvador and Lloret (1995) for Phillyrea latifolia $\mathrm{L}$. and (ii) mechanical scarification by removal of the seed coat, following García-Fayos (2001) and Piotto and Di Noi (2001). After a soaking period of $24 \mathrm{~h}$, the seeds were set to germinate at $25{ }^{\circ} \mathrm{C}$ during the 14 -week monitoring period. The third treatment involved a different experimental setup, with four replicates that each comprised 25 randomly selected seeds per mother-plant. The treatment itself involved the same pre-treatment of mechanical scarification as described before, which was then followed by overnight soaking and placing the seeds over moist filter paper. The germination conditions of this third additional treatment differed markedly from those of the other $P$. angustifolia experiments, since the seeds were placed in a germination chamber under dark conditions and at alternating temperatures of 10 and $20^{\circ} \mathrm{C}(12 \mathrm{~h})$, following Garcia-Fayos (2001).

\subsection{Data analysis}

The cumulative germination percentages at the end of the 14 weeks monitoring period were first analysed by means of two-way ANOVA, using storage treatment and seed source as factors. In case these factors had a significant overall effect, the individual contrasts between treatments and/or seed sources were tested using Tukey's HDS post hoc test. The role of the treatments was also assessed for each seed source separately, using one-way ANOVA and Tukey's HDS post hoc test. The assumptions underlying ANOVA were assessed by visual inspection of the distribution of the residuals as well as by testing homoscedasticity by means of the Levene's test. In the case of P. lentiscus and A. unedo, the assumption of 
homoscedasticity was met by transforming the germination percentages to $\ln (x+1)$ and sqrt $(x)$, respectively. In the case of $P$. angustifolia, however, no standard transformation allowed to pass the Levene's test. Therefore, the overall importance of treatment and seed source in the germination percentages of $P$. angustifolia were tested separately, using the nonparametric Kruskal-Wallis test. The role of treatment was also tested for each of the individual $P$. angustifolia seed sources separately, using the Kruskal-Wallis test in combination with the Dunn's test for evaluating the different contrasts between treatments. The results of the statistical tests were considered significant at $\alpha \leq 0.05$. All statistical analyses were carried out using SPSS v. 18 .

\section{Results}

\subsection{Overall effects of pre-germination treatments}

In the control treatments, the three species differed noticeably in the time that they took to germinate (Fig. 1). The maximum germination percentages were attained much faster by the species lacking dormancy, P. lentiscus, than by the two species with physiological or physical dormancy, i.e. after 2-3 weeks in opposition to 12-14 weeks.

The three species also responded differently to the three storage treatments (Table 2). The final germination percentages of the species lacking dormancy, P. lentiscus, differed significantly among the three treatments, whereas the final germination of the two species with physical or physiological dormancy did not. In the case of $A$. unedo, the role of treatment depended in a significant manner on seed source, as revealed by the significant interaction term in the two-way ANOVA results (Table 2). In the case of $P$. angustifolia, the overall treatment effect was not significant, probably reflecting the poor germination observed in all replicate tests of the three common treatments. Germination of $P$. angustifolia was not substantially enhanced by either of the two additional treatments that involved germination under unvarying conditions of temperature. Final germination percentages remained below $5 \%$ following the pre-treatments of both heat exposure and mechanical scarification. By contrast, the third additional treatment which combined mechanical scarification with alternating temperature conditions during germination resulted in final germination percentages of approximately $85 \%$.

The significant overall treatment effect on P. lentiscus germination reflected a negative effect of cold storage under high moisture conditions. The results of the Tukey post hoc tests showed that the final germination percentages were significantly lower (7\%) following cold storage under high moisture conditions than following cold storage under low moisture conditions $(18 \% ; p<0.01)$ as well as under control conditions $(13 \% ; p<0.05)$.

\subsection{Overall role of seed source}

Seed source had a significant overall effect on final germination percentages in the case of $P$. lentiscus as well as in the case of $P$. angustifolia (Table 2), even though in the last species, a possible interaction with treatment effect could not be tested due to the lack of homoscedasticity (as detailed in 2.4). In the case of $A$. unedo, the role of seed source differed according to the treatments, as evidenced by the significant interaction between these two factors.

The significant overall effect of seed source on the germination of $P$. lentiscus coincided with significantly higher germination percentages for the seeds from the northern sampling $(17 \%)$ location than from the central location $(7 \% ; p<0.01)$, independent of the three common treatments (interaction: $p=0.15$ ). There was furthermore some indication that the northern seeds of $P$. lentiscus also germinated better than its southern seeds. In the case of the HM treatment, the difference between the two seed sources was not only marginally significant $(p=0.08)$ but also noticeably (Fig. 1). In the case of $P$. angustifolia, the overall importance of seed source corresponded to significantly higher germination percentages for the southern $(3 \%)$ than central population $(0 \%)$. These differences were maintained following a successful protocol for germination enhancement (mechanical scarification plus germination at alternating temperatures), amounting 81 and $88 \%$ for the central and southern seed source, respectively.

\subsection{The effect of treatment within seed source}

The final germination percentages of $P$. lentiscus differed in a consistent manner between the three storage treatments for the individual seed sources (Fig. 1). They increased from LM to control and to HM conditions. These differences between treatments appeared to increase along the geographical sampling gradient, from the northern to the central to the southern population (Fig. 1). This geographical pattern was also sustained by the one-way ANOVA results for the individual seed sources (Table 3). They revealed that the treatment-wise differences in final germination percentages were significant in the case of both the central population and the southern population, but not in the case of the northern population. The subsequent Tukey post hoc tests confirmed the overall tendency of a negative effect of cold storage under high as compared to under low moisture conditions (central and southern: $p<0.05$ ).

In the case of $A$. unedo, the final germination percentages of the three common treatments only differed significantly for the seeds from the central population (Table 2). This significant difference corresponded to a positive effect of cold 
No dormancy

(Pistacia lentiscus)
Physiological dormancy

(Arbutus unedo)
Physical dormancy (Phillyrea angustifolia) $-\not-$ Control $\mp$ Cold-LM $\longrightarrow$ Cold-HM

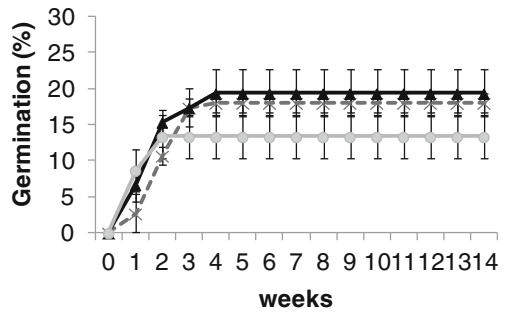

$-\star-$ Control $\rightarrow$ Cold-LM $\rightarrow-$ Cold-HM

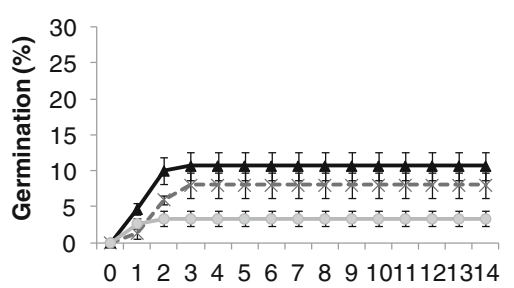

weeks

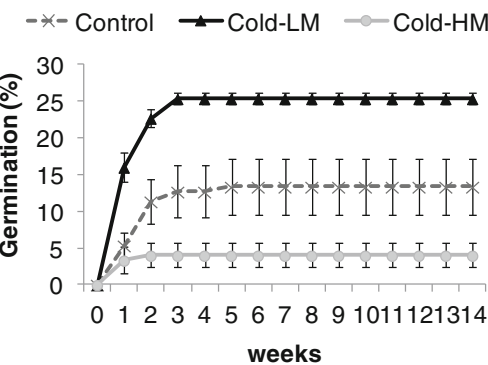

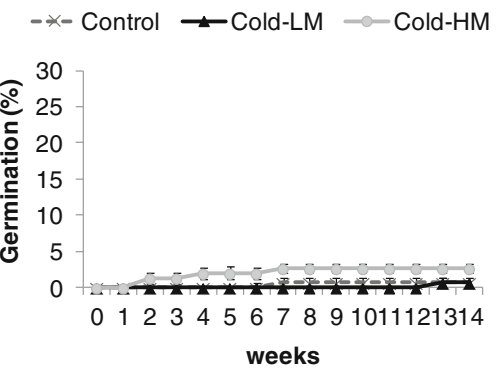
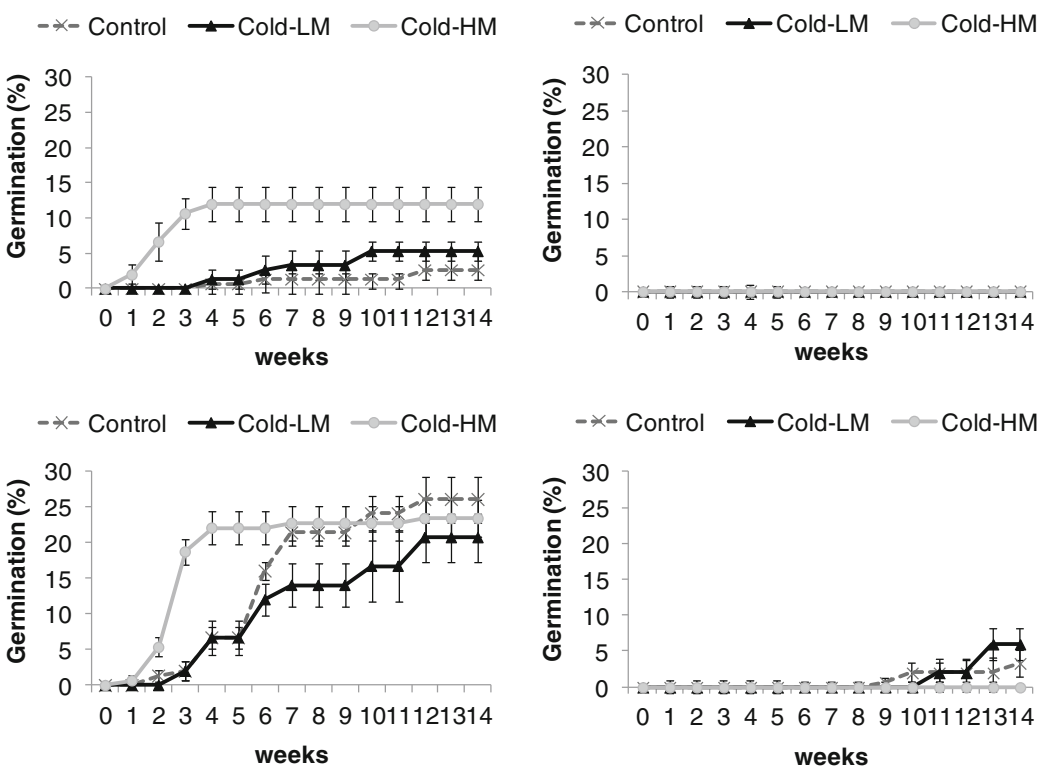

two to three contrasting sources in mainland Portugal (see Table 1) that were stored under standard conditions (control) as well as at low temperatures under low (LM) and high (HM) moisture conditions

positive impact of cold storage under high moisture conditions was also suggested by various other instances, i.e.: (i) in the

Table 3 Statistical test results for the role of seed storage treatment in the germination percentages of $P$. lentiscus and A. unedo (using one-way ANOVA) as well as $P$. angustifolia (using the Kruskal-Wallis test) for the $2-3$ studied seed sources

Table 2 Statistical test results of the role of seed storage treatment and source in the germination percentages of $P$. lentiscus and $A$. unedo (using two-way ANOVA) as well as $P$. angustifolia (using Kruskal-Wallis test)

\begin{tabular}{lllll}
\hline & & Treatment & $\begin{array}{l}\text { Seed } \\
\text { source }\end{array}$ & $\begin{array}{l}\text { Treatment } \times \text { seed } \\
\text { source }\end{array}$ \\
\hline Pistacia lentiscus & $F$ & 11.26 & 7.1 & 1.83 \\
Arbutus unedo & $p$ & $<0.01$ & $<0.01$ & 0.15 \\
& $F$ & 6.13 & 81.79 & 3.02 \\
Phillyrea angustifolia & $p$ & 0.01 & $<0.01$ & 0.03 \\
& QS & 4.49 & 8.64 & - \\
& $p$ & 0.11 & $<0.01$ & - \\
\hline
\end{tabular}

The treatments tested involved storage under standard conditions (control) as well as at cold temperatures under either low (LM) or high moisture (HM) conditions. Significant results (at $\alpha \leq 0.05$ ) were presented in italics

\begin{tabular}{lllll}
\hline & & \multicolumn{3}{l}{ Treatment differences } \\
\cline { 3 - 5 } & & Northern & Central & Southern \\
\hline Pistacia lentiscus & $F$ & 1.76 & 4.59 & 5.64 \\
Arbutus unedo & $p$ & 0.21 & 0.03 & 0.02 \\
Phillyrea angustifolia & $F$ & 3.00 & 6.28 & 0.75 \\
& $p$ & 0.09 & 0.01 & 0.49 \\
& QS & - & 0.00 & 6.71 \\
& $p$ & - & 1.00 & 0.03 \\
\hline
\end{tabular}

The treatments tested involved storage under standard conditions (control) as well as at cold temperatures under either control conditions (CT) and low (LM) or high moisture conditions (HM). Significant results (at $\alpha \leq 0.05$ ) were presented in italics 
case of the central seed source, the lower germination percentages following cold storage under dry conditions; (ii) in the case of the northern seed source, the lower germination percentages of the other two treatments; (iii) in the case of the southern seed source, the slower initial germination response of the other two treatments during weeks 2 to 6 .

In the case of $P$. angustifolia, none of the three common treatments resulted in the germination of even a single seed from the central population. However, they differ significantly in the final germination percentages of the southern seeds (Table 2). This significant difference corresponded to a negative impact of cold storage under high $(0 \%)$ as opposed to under low moisture conditions (6\%; Dunn's: $p<0.05)$.

\section{Discussion}

The present study found that seed storage conditions had distinct effects on the germination of three Mediterranean shrub species that had been selected to represent contrasting types of dormancy (physiological, physical, no dormancy) in autumnwinter dispersed seeds. Temporary storage under high-moisture cold conditions enhanced germination in A. unedo, had no effect on germination in $P$. angustifolia and reduced germination in P. lentiscus. These contrasting results agreed well with the hypotheses that were inferred from the species' dormancy types. A cold stimulus under high moisture conditions was hypothesized to break the physiological dormancy of A. unedo seeds, to be negligible for the physical dormancy in $P$. angustifolia seeds, and to lead to viability losses in the nondormant seeds of $P$. lentiscus. In addition, the germination results that were obtained in the control treatment without temporary cold storage fitted in well with differences in type of dormancy. The seeds of $P$. lentiscus germinated faster than the seeds with - physical or physiological - dormancy, while the seeds of $P$. angustifolia germinated clearly less well than the non-dormant seeds or the seeds with physiological dormancy.

In general, the final germination percentages produced by the control treatment agreed well with the results reported by previous studies. In the case of $A$. unedo, most prior studies found very low germination percentages, varying between 0 and $5 \%$ (Smiris et al. 2006: $0 \%$; Demirsoy et al. 2010:1-3\%; Tilki 2004: 4 \%; Ertekın and Kırdar 2010: 5 \%). Hammami et al. (2005), however, obtained a considerably better result (19\%). In the case of P. lentiscus, the present results were of the same order of magnitude as the results reported by Quaoud (2007: $10 \%$ ) but they were considerably lower than the those obtained by Piotto and Di Noi (2001: 40-80 \%). In the case of $P$. angustifolia, prior germination studies seemed to be lacking. Nonetheless, similar to this study, Takos and
Efthimiou (2003) obtained essentially no germination for P. latifolia seeds.

The positive effects of temporary cold storage on the germination of $A$. unedo reported here were in line with the findings of prior studies (Demirsoy et al. 2010; Ertekın and Kırdar 2010; Tilki 2004). The degree of germination enhancement in this study was of the same order of magnitude as that in Demirsoy et al. (2010: +3-20 \%) but was markedly less than in Ertekin and Kirdar (2010:50 \%) and especially in Tilki (2004: $80 \%$ ). These discrepancies in germination enhancement could involve, among other factors, differences in the degree of dormancy that, in turn, could be related to the use of different seed sources. Even so, the maximum temperature threshold for germination in $A$. unedo seems to be relatively lower than the standard temperatures used in germination essays $\left(20-25^{\circ} \mathrm{C}\right)$. Markedly higher germination percentages (above 70-80 \%) were observed in other studies using lower germination temperatures $\left(10-15^{\circ} \mathrm{C}\right.$; Bertsouklis and Papafotiou 2013; Vasques et al. 2013). This typical Mediterranean germination response (Fenner and Thompson 2005; Bertsouklis and Papafotiou 2013) explains the low germination percentages of $A$. unedo that were observed in this as well as in most of the prior studies (Tilki 2004; Smiris et al. 2006; Demirsoy et al. 2010; Ertekın and Kırdar 2010).

The degree of dormancy can influence the temperature thresholds for germination, with a decrease in dormancy broadening the range of temperatures that favour germination (Gutterman 2000). In turn, the degree of dormancy usually decreases in response to higher temperatures during seed development (Long et al. 2014). In the case of A. unedo, the observed increase in germination percentages along the sampling gradient from northern to southern Portugal agreed with a decrease in the degree of dormancy with increasing mean annual temperatures. The same tendency for higher germination in southern populations was also observed in $P$. angustifolia. Such a geographical pattern the degree of dormancy or sensitivity to dormancy breaking factors could represent an adaptation, by allowing A. unedo and $P$. angustifolia seeds to germinate earlier in regions where favourable temperatures occur earlier after seed dispersal.

The present finding that germination in P. lentiscus was negatively affected by cold storage under high moisture conditions contrasted with the results obtained by Quaoud (2007) as well as Piotto (1995). The former author observed a marked increase in germination (20\%), while the latter author reported a noticeable acceleration of germination in $P$. lentiscus. These contrasting results could be due to differences in the duration of the cold treatment, since the cold storage was more than twice as long in the present study (70 days) than in those of Quaoud (2007: 21 days) and Piotto (1995: 30 days). An increasing loss of seed viability with increasing storage period would agree with the finding of García-Fayos and Verdú (1998) that 
P. lentiscus seeds exhibited a poor persistence in the soil seed bank.

Some of the differences in germination response between the seed sources could be interpreted as adaptive traits. For example, cold storage under high moisture conditions would not be expected to decrease germination in seeds from northern Portugal, since the region has a comparatively higher rainfall. By contrast, cold storage under high moisture conditions would be expected to decrease germination in seeds from a southern population, whereas cold storage under dry conditions would perhaps not.

The present findings seem relevant to the understanding of the ecology of Mediterranean plant communities that suffer frequent and/or severe disturbances, further aggravated by the foreseen climate changes of rising temperatures and more frequent and severe drought events (Solomon 2007). Germination on both P. angustifolia and A. unedo would be sensitive to changes in temperature regimes. In particular, germination in A. unedo could be hampered by a decline in cold and wet conditions during winter, which are required to reduce its degree of dormancy, as well as by an increase in temperatures during spring, which could inhibit germination. By contrast, various companion species of the studied species could be favoured by the foreseen climate changes, possibly leading to a shift in floristic composition. This is the case of various Mediterranean shrub species of the Cistaceae, Ericaceae and Leguminosae families and, in particular, those that form a permanent soil seed bank and whose dormancy is broken by dry and warm conditions (Vasques et al. 2012; Santana et al. 2013). Several of these species can markedly increase fuel load accumulation and therefore a shift in species composition could furthermore increase fire hazard, which in its turn could enhance ecosystem degradation (Pausas et al. 2012).

In this context, the storage of P. lentiscus seeds in the soil could be favoured by the foreseen drier and warmer winter conditions. Palacio et al. (2005) attributed the thermophilous distribution of $P$. lentiscus to the extended phenological activity of its canopy, which leads to the exposure of buds to cold winter. The present findings could, however, also contribute to explain the limits of distribution of this species since the observed low tolerance of the seeds to high moisture cold conditions could constrain the successful colonization of habitats with higher rainfall.

Finally, the observed differences in germination response among seed sets from different sources can improve the accuracy of high disturbance scenarios and/or climate change predictions by including the value of plant population adaptation. However, to fully understand the consequences of such site-related adaptations, their speed, degree and reversibility should be disentangled, namely by researching their origin and consequences under variable environmental conditions.

\section{Conclusions}

The present study allowed drawing five main conclusions on the germination ecology of three Mediterranean shrub species that were selected for their elevated potential for ecological restoration, on the one hand, and, on the other, for their contrasting dormancy types in their autumn-winter dispersed seeds. These five conclusions were the following: (i) A. unedo, P. angustifolia and P. lentiscus differed markedly in their germination responses to cold storage treatments simulating conditions in the soil seed bank following dispersal; (ii) the distinct responses, especially in terms of germination percentages, agreed well with the presence/absence and type of dormancy in these species, with cold storage under humid conditions enhancing germination in A. unedo (physiological dormancy), reducing it in P. lentiscus (no dormancy) and not affecting it in P. angustifolia (physical dormancy); (iii) seed source was a key factor in the germination response of all three species, either by having a significant overall effect or by having a significant effect that depended on the storage treatments; (iv) some of the seed source-related differences in germination behaviour could involve adaptive traits, as they seemed to fit well with the differences in climate conditions at the seed harvesting sites; (v) the role of mother plant life story as well as environmental conditions during seed development in seed dormancy degree or sensitivity to dormancy breaking factors require further research, including to improve protocols for seed harvesting, seed storage and germination tests in Mediterranean shrub species.

Acknowledgments The authors are grateful to ICNB for the permission to collect seeds in the Portuguese territory and also to Alexandra Pinheiro, Carlota Vaz, Diana Vieira and Paula Maia for their kind help in seed harvesting. We also want to acknowledge Banc de Llavors Forestalls of Valencia for their availability to provide seed handling supervision. We are also grateful to João Nunes, Maria Rial, Raquel Ferreira and Sergio Prats for their help in monitoring the best time for seed harvesting, and to Armando Costa, Celeste Dias, Cristina Monteiro, Isabel Fernandes and Glória Pinto for their logistical support in the laboratory. Finally, we would like to thank the four anonymous reviewers for their comments that contributed very much to the improvement of this manuscript.

Funding This study was funded by the Portuguese Foundation for Science and Technology (FCT) and QREN through the first author's $\mathrm{PhD}$ grant (SFRH/BD/47522/2008).

\section{References}

Baskin J, Baskin C (2004) A classification system for seed dormancy. Seed Sci Res 14:1-16

Bertsouklis KF, Papafotiou M (2013) Seed germination of Arbutus unedo, A. andrachne and their natural hybrid A. Andrachnoides in relation to temperature and period of storage. Hort Sci 48: 347-351 
Bischoff A, Steinger T, Müller-Schärer H (2008) The importance of plant seed source and genotypic diversity of seed material used for ecological restoration. Res Ecol 18:338-348

Cardoso JC, Bessa MT, Marado MB (1973) Carta dos solos de Portugal $(1: 1,000,000)$. Agron Lusit 33:461-602

Cerabolini B, Ceriani RM, Caccianiga M, De Andreis R, Raimondi B (2003) Seed size and shape and persistence in soil: a test on Italian flora from Alps to Mediterranean coasts. Seed Sci Res 13:75-86

Demirsoy L, Demirsoy H, Celikel G, Macit I, Ersoy B (2010) Seed treatment with GA 3 or stratification enhances emergence of some strawberry tree genotypes - short communication. Hort Sci 37:34-37

Díaz-Delgado R, Lloret F, Pons X, Terradas J (2002) Satellite evidence of decreasing resilience in Mediterranean plant communities after recurrent wildfires. Ecol 83:2293-2303

Directiva Habitats - Directiva 92/43/CEE do Conselho,de 21 de Maio de (1992) transposta para o direito interno de Portugal pelo Decreto-Lei n. ${ }^{\circ} 140 / 99$, de 24 de Abril

Engelmann F, Engels JMM (2002) Technologies and strategies for ex situ conservation. Managing plant genetic diversity. CABI Publishing, UK, pp 89-103

Ertekın M, Kirdar E (2010) Breaking seed dormancy of the strawberry tree (Arbutus unedo). Int J Agric Biol 12:57-60

Fenner M, Thompson K (2005) The ecology of seeds. Cambridge University Press, UK, pp 67-71; 76-109: 116-123

Finch-Savage WE, Leubner-Metzger G (2006) Seed dormancy and the control of germination. New Phyt 171:501-523

García-Fayos P (2001) Bases ecológicas para la recolección, almacenamiento y germinación de semillas de especies de uso forestal en la Comunidad Valenciana. Book ID: 6170. Generalitat Valenciana, Spain

García-Fayos P, Verdu M (1998) Soil seed bank, factors controlling germination and establishment of a Mediterranean shrub : Pistacia lentiscus L. Acta Oecol 19:357-366

Gutterman Y (2000) Maternal effects on seeds during development. In: Fenner M (ed) Seeds - the ecology of regeneration in plant communities, 2nd edn. CAB, USA, pp 76-77

Hammami I, Jellali M, Ksontini M, Rejeb M (2005) Propagation of the strawberry tree through seed. Int J Agric Biol 7:457-459

Herrera CM (1984) A study of avian frugivores, bird-dispersed plants, and their interaction in Mediterranean scrublands. Ecol Monogr 54: $1-23$

Herrera CM (1989) Frugivory and seed dispersal by carnivorous mammals, and associated fruit characteristics, in undisturbed Mediterranean habitats. Oikos 55:250-262

Hufford KM, Krauss SL, Veneklaas EJ (2012) Inbreeding and outbreeding depression in Stylidium hispidum: implications for mixing seed sources for ecological restoration. Ecol Evol 2: 2262-2273

IPAM. Portuguese Institute of the Sea and Atmosphere, available online at https://www.ipma.pt/pt/oclima/normais.clima/, last accessed August 2013

JBUTAD, Digital Flora Online. Botanic Garden of UTAD, Portugal; available online at http://jb.utad.pt/flora, last accessed April 2014

Liodakis S, Kakardakis T (2008) Measuring the relative particle foliar combustibility of WUI forest species located near Athens. J Therm Ana Cal 93:627-635

Long RL, Gorecki MJ, Renton M, Scott JK, Colville L, Goggin DE, Finch-Savage WE (2014) The ecophysiology of seed persistence: a mechanistic view of the journey to germination or demise. Biol Rev Camb Philos Soc. doi:10.1111/brv.12095

Merritt DJ, Dixon KW (2011) Restoration seed banks - a matter of scale. Science 332:424-425

Mijnnsbrugge K, Bischoff A, Smith B (2010) A question of origin: where and how to collect seeds for ecological restoration. Bas App Ecol 11: 300-311
Milberg P, Andersson L (1998) Does cold stratification level out differences in seed germinability between populations? Plant Ecol 134: 225-234

Murdoch A, Ellis R (2000) Dormancy, viability and longevity. In: Fenner $M$ (ed) Seeds - the ecology of regeneration in plant communities, 2nd edn. CAB, USA, pp 183-214

Oliveira G, Nunes A, Clemente A, Correia O (2011) Testing germination of species for hydroseeding degraded Mediterranean areas. Rest Ecol. doi:10.1111/j.1526-100X.2011.00816.x

Palacio S, Milla R, Montserrat-Martí G (2005) A phenological hypothesis on the thermophilous distribution of Pistacia lentiscus L. Flora 200: $527-534$

Pausas J, Llovet J, Rodrigo A, Vallejo R (2008) Are wildfires a disaster in the Mediterranean basin? A review. Int J Wildland Fire 17: $713-723$

Pausas JG, Alessio G, Moreira B, Corcobado G (2012) Fires enhance flammability in Ulex parviflorus. New Phytol 193:18-23

Peel MC, Finlayson BL, McMahon TA (2007) Updated world map of the Köppen-Geiger climate classification. Hydrol Earth Syst Sci Discuss 4:439-473

Penfield S, Josse EM, Kannangara R, Gilday AD, Halliday KJ, Graham IA (2005) Cold and light control seed germination through the bHLH transcription factor SPATULA. Curr Biol 15: 1998-2006

Piotto E (1995) Influence of scarification and prechilling on the germination of seeds of Pistacia lentiscus. Seed Sci Tech 23: 659-663

Piotto E, Di Noi A (2001) Seed propagation of Mediterranean trees and shrubs. APAT - Agency for the protection of the environment and for technical services, Roma

Pratt RB, Jacobsen AL, Ramirez AR, Helms AM, Traugh CA, Tobin MF, Heffner MS, Davis SD (2013) Mortality of resprouting chaparral shrubs after a fire and during a record drought: physiological mechanisms and demographic consequences. Glob Chang Biol 20: 893-907

Qaoud (2007) Effect of scarification, gibberellic acid and stratification on seed germination of three Pistacia species. J Res 21: $1-11$

Roberts EH (1973) Predicting the storage life of seeds. Seed Sci Tec 1: 499-514

Salvador R, Lloret F (1995) Germinación en el laboratorio de varias especies arbustivas mediterráneas: efecto de la temperatura. Orsis 10:25-34

Santana VM, Baeza MJ, Blanes MC (2013) Clarifying the role of fire heat and daily temperature fluctuations as germination cues for Mediterranean Basin obligate seeders. Ann Bot - London 111: $127-134$

Scarascia-Mugnozza G, Oswald H, Piussi P, Radoglou K (2000) Forests of the Mediterranean region: gaps in knowledge and research needs. Forest Ecol Manag 132:97-109

Smiris P, Pipinis E, Aslanidou M, Mavrokordopoulou O, Milios E, Kouridakis A (2006) Germination study on Arbutus unedo L. (Ericaceae) and Podocytisus caramanicus Boiss. \& Heldr (Fabaceae). J Bio Res 5:85-91

Solomon S (Ed.) (2007) Climate change 2007-the physical science basis: Working group I contribution to the fourth assessment report of the IPCC (Vol. 4). Cambridge University Press

Taiz L, Zeiger E (2010) A companion to plant physiology, Fifth Edition, Ch 23.18, Sinauer Associates, available online at http://5e. plantphys.net/article.php?ch $=23 \& i d=8$, last accessed November 2013

Takos IA, Efthimiou GS (2003) Germination results on dormant seeds of fifteen tree species autumn sown in a Northern Greek nursery. Silv Gen 52:67-71

Tilki F (2004) Improvement in seed germination of Arbutus unedo L. Pakistan J Bio Sci 7:1640-1642 
Tischew S, Youtie B, Kirmer A, Shaw N (2011) Farming for restoration: building bridges for native seeds. Ecol Rest 29:219-222

Vallejo VR, Aronson J, Pausas JC, Cortina J (2005) Restoration of Mediterranean woodlands. In: van Andel J, Aronson J (eds) Restoration ecology: a European perspective. Blackwell Science, Oxford, pp 193-207

Vallejo VR, Smanis A, Chirino E, Fuentes D, Valdecantos A, Vilagrosa A (2012) Perspectives in dryland restoration: approaches for climate change adaptation. New For. doi:10.1007/s11056-012-9325-9

Vasques A, Maia P, Pedro M, Santos C, Vallejo R, Keizer J (2012) Germination in five shrub species of Maritime Pine understorydoes seed provenance matter? Ann For Sci 69:499-507
Vasques A, Chirino E, Vilagrosa A, Vallejo VR, Keizer JJ (2013) The role of seed provenance in the early development of Arbutus unedo seedlings under contrasting watering conditions. Environ Exp Bot 96:11-19

Venable DL, Brown JS (1988) The selective interactions of dispersal, dormancy, and seed size as adaptations for reducing risk in variable environments. Am Nat 131:360-384

Verdú M, García-Fayos P (1998) Ecological causes, function, and evolution of abortion and parthenocarpy in Pistacia lentiscus (Anacardiaceae). Can J Bot 76:134-141

Verdú M, García-Fayos P (2000) The effect of deceptive fruits on seed pre-dispersal by birds in Pistacia lentiscus. Plant Ecol 0:1-4 